\title{
A Qualitative Study of How Health Coaches Support Patients in Making Health-Related Decisions and Behav- ioral Changes
}

\author{
David H. Thom, MD, PbD \\ Jessica Wolf, BS \\ Heather Gardner, MPH \\ Denise DeVore, BA \\ Michael Lin, BS \\ Andy Ma, BS \\ Ana Ibarra-Castro \\ George Saba, PbD \\ Center for Excellence in Primary Care, \\ Department of Family and Community \\ Medicine, University of California, San \\ Francisco School of Medicine, San Fran- \\ cisco, California
}

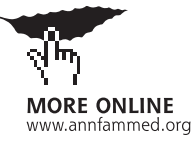

Conflicts of interest: authors report none.

\section{CORRESPONDING AUTHOR}

David H. Thom, MD, PhD

Building 80/83

1001 Potrero Ave

San Francisco, CA 94110

David.Thom@UCSF.edu

\begin{abstract}
PURPOSE Although health coaches are a growing resource for supporting patients in making health decisions, we know very little about the experience of health. We undertook a qualitative study of how health coaches support patients in making decisions and implementing changes to improve their health.
\end{abstract}

METHODS We conducted 6 focus groups ( 3 in Spanish and 3 in English) with 25 patients and 5 friends or family members, followed by individual interviews with 42 patients, 17 family members, 17 health coaches, and 20 clinicians. Audio recordings were transcribed and analyzed by at least 2 members of the study team in ATLAS.ti using principles of grounded theory to identify themes and the relationship between them.

RESULTS We identified 7 major themes that were related to each other in the final conceptual model. Similarities between health coaches and patients and the time health coaches spent with patients helped establish the health coachpatient relationship. The coach-patient relationship allowed for, and was further strengthened by, 4 themes of key coaching activities: education, personal support, practical support, and acting as a bridge between patients and clinicians.

CONCLUSIONS We identified a conceptual model that supports the development of a strong relationship, which in turn provides the basis for effective coaching. These results can be used to design health coach training curricula and to support health coaches in practice.

Ann Fam Med 2016;14:509-516. doi: 10.1370/afm.1988.

\section{INTRODUCTION}

$\mathrm{R}$ ecent efforts to provide more integrated, patient-centered primary care have included patient activation, patient education and engagement, shared decision making, and self-management support. Health coaches work in all of these areas, providing patients with health-related information, navigational support, connections to community resources, and personal support. ${ }^{1,2}$ Coaches focus on helping patients to identify goals, create plans to make changes, and implement changes. Although health coaching can be performed by licensed professionals including nurses, physical therapists and respiratory therapists, ${ }^{3,4}$ or by other patients (peer support), ${ }^{5-8}$ medical assistants ${ }^{19,10}$ and other unlicensed health workers (eg, community health workers, lay health advisers, and promotoras ${ }^{11-16}$ are emerging as a common and relatively economical workforce that may meet the demand for self-management support. Health coaching has been proposed as an inexpensive and effective means to improve control of chronic conditions ${ }^{1}$ and has been effective in improving management of diabetes and other risk factors for cardiovascular disease, asthma, and chronic obstructive pulmonary disease. , $5,9,10,17-19$ Coaches may be particularly valuable in resource-poor settings, where minority and low-income communities bear a disproportionate burden of chronic disease and its 
complications, and are less likely to engage in effective self-management of their conditions..$^{20}$ In these settings, clinics can often employ coaches who culturally and linguistically match the patients' characteristics. ${ }^{21}$

Health coaches in primary care usually work with patients on everyday decisions such as taking medications, engaging in physical activity, and making dietary changes. ${ }^{22}$ Although previous qualitative studies have investigated shared decision making between patients and clinicians, and self-management support for patients by care coordinators, little research exists on how health coaches support patients in making decisions and changing behaviors.

\section{METHODS}

To develop a better understanding of how health coaches work with patients, we conducted a qualitative study using focus groups and individual interviews with patients, their family and friends, health coaches, and clinicians, with the goal of creating a conceptual model describing the process of health coaching. The study was approved by the University of California San Francisco Committee on Human Research. Data were collected between May 9, 2013, and July 8, 2014.

\section{Participants and Setting}

The study was conducted at 6 urban public health primary care clinics serving low-income patients that have used health coaches for several years. All health coaches were medical assistants or other allied nonlicensed health workers who received 40 hours of training ${ }_{1}^{23}$ which included instruction in active listening and nonjudgmental communication; self-management support; social and emotional support; assistance with lifestyle change; basic education about patients' chronic conditions, including the importance of medication adherence, navigating the clinic; and accessing community resources. ${ }^{10}$ Although the content of the training was based in part on existing models such as the Chronic Care Model ${ }^{24}$ and Motivational Interviewing ${ }_{1}^{25,26}$ no single theoretical model determined the content or processes of training. Participants were drawn from all current and recent health coaches at the 6 clinics, all patients who received coaching, their primary care clinicians, and their families or friends whom they identified as involved in their care. Most health coaches were bilingual in Spanish and English, and all patients spoke either Spanish or English.

\section{Recruitment and Enrollment}

All health coaches who were working or who had recently worked at each of the 6 clinics were identified by clinic managers and other coaches. Patients who had received health coaching were then identified from the health coaches' panels and were recruited in person at the time of a clinic visit or by telephone. Informed consent was obtained in person immediately before the focus group or interview. Health coaches and licensed clinicians (physicians, nurse practitioners, or physician assistants) whose patients received health coaching were invited by e-mail or telephone by a research assistant.

\section{Data Collection}

Six focus groups (3 in English and 3 in Spanish) lasting approximately 90 minutes each were conducted using a semistructured format. Individual interviews were subsequently conducted by 2 bilingual (Spanish and English) research staff (H.G. and J.W.), either in person (61 interviews) or by telephone (36 interviews). Interviewers used question guides that were developed based on the goals of the study and were reviewed and revised by members of the study's advisory board (5 patients, 3 health coaches, 4 primary care clinicians, and a national expert). Question guides were pilot-tested on a convenience sample of patients and revised to improve clarity and flow. For both focus groups and interviews, patients were initially asked to think about a health decision defined as "deciding to do something new, or to change or stop doing something you are already doing. For example, a health decision could be to cut down or stop smoking, to walk 4 blocks every morning, to get a flu shot, or to take or not take a medication as prescribed." Family members, health coaches, and clinicians were asked the same question, rephrased to be appropriate. The guide template and probe questions are provided in the Supplemental Appendix (available online at http://www.annfammed.org/content/14/6/509/suppl/ DC1). All focus groups and interviews were audiorecorded and transcribed. Interviews conducted in Spanish were transcribed in both Spanish and English.

\section{Data Analysis}

The core team consisted of a family physician with prior experience in medical qualitative research (D.H.T.), a clinical psychologist with prior qualitative research experience (G.S.), an MPH-trained study coordinator with experience in qualitative research for program evaluation (H.G.), and a research assistant with previous experience in clinical research (J.W.). Although analysis of the data was informed by knowledge of the content of coach training, we did not set out to accept or reject specific characteristics of health coaching implied from the training, but rather to use a more inductive approach to allow the emergence of unanticipated themes and relationships.

For analysis, transcribed data were stripped of personal identifying information and imported into 
ATLAS.ti qualitative research software (ATLAS.ti Scientific Software Development GmbH). We used multistaged coding based on grounded theory. 27,28 All transcripts were independently read by at least 2 members of the study team, with discrepancies in the assignment of codes resolved either between the readers or by the entire group if necessary. Initially, readers assigned descriptive labels to key passages, and similar labels were grouped to create an initial set of "concept codes" (open coding). Focus group data were analyzed first to create an initial set of codes as the starting point for analysis of the interview data. During analysis of the interview data, additional codes were added and concept codes were modified by group consent. Concept codes were then combined into broader "category codes" and organized into themes through group discussion and consensus reasoning (axial coding). This process included disaggregation of the category codes and reorganization of the original concept codes for some codes. During the final step, we considered alternative models to describe the relationship between themes (selective coding), reviewing concept and category codes as needed, to create a consensus conceptual model. All themes were identified based on shared experiences from members of all 4 groups (patients, family and friends, health coaches, and clinicians), and we counted the number of individuals in each group who shared 1 or more experiences that contributed to each theme. Because it was not possible to reliably assign quotes to individuals in focus groups, these counts were based on individual interviews. During the analysis, we actively searched for passages that contradicted the coding structure. We also sought to validate the concept and category codes we developed by presenting them to the study advisory board for their comments and suggestions.

\section{RESULTS}

\section{Study Sample}

We identified 191 patients who received coaching. Of these 191 patients, 120 were contacted and 59 were enrolled; 25 participated in a focus group and 42 were interviewed ( 8 focus group patients were also interviewed). The primary reason for nonparticipation was not being available at the time scheduled for the focus group or interview. Of the 29 family or friends identified by participating patients as involved in their care, 17 (59\%) were interviewed; of the 23 health coaches at the 6 clinic sites, $17(74 \%)$ were interviewed; of the 29 primary care clinicians for the enrolled patients, 21 (72\%) were interviewed and 20 provided data (the recording for 1 clinician interview was inaudible).

Characteristics of study participants are shown in Table 1. Compared with nonenrolled patients, those enrolled were less likely to speak Spanish (46\% vs $82 \%$ ) but equally likely to be female ( $64 \%$ vs $63 \%$ ). Of the 20 clinicians with interview data, 17 were physicians, 2 were nurse practitioners, and 1 was a physician assistant. The majority of patients reported having worked with their health coach for a year or longer.
Table 1. Participant Characteristics $(\mathrm{N}=118)$

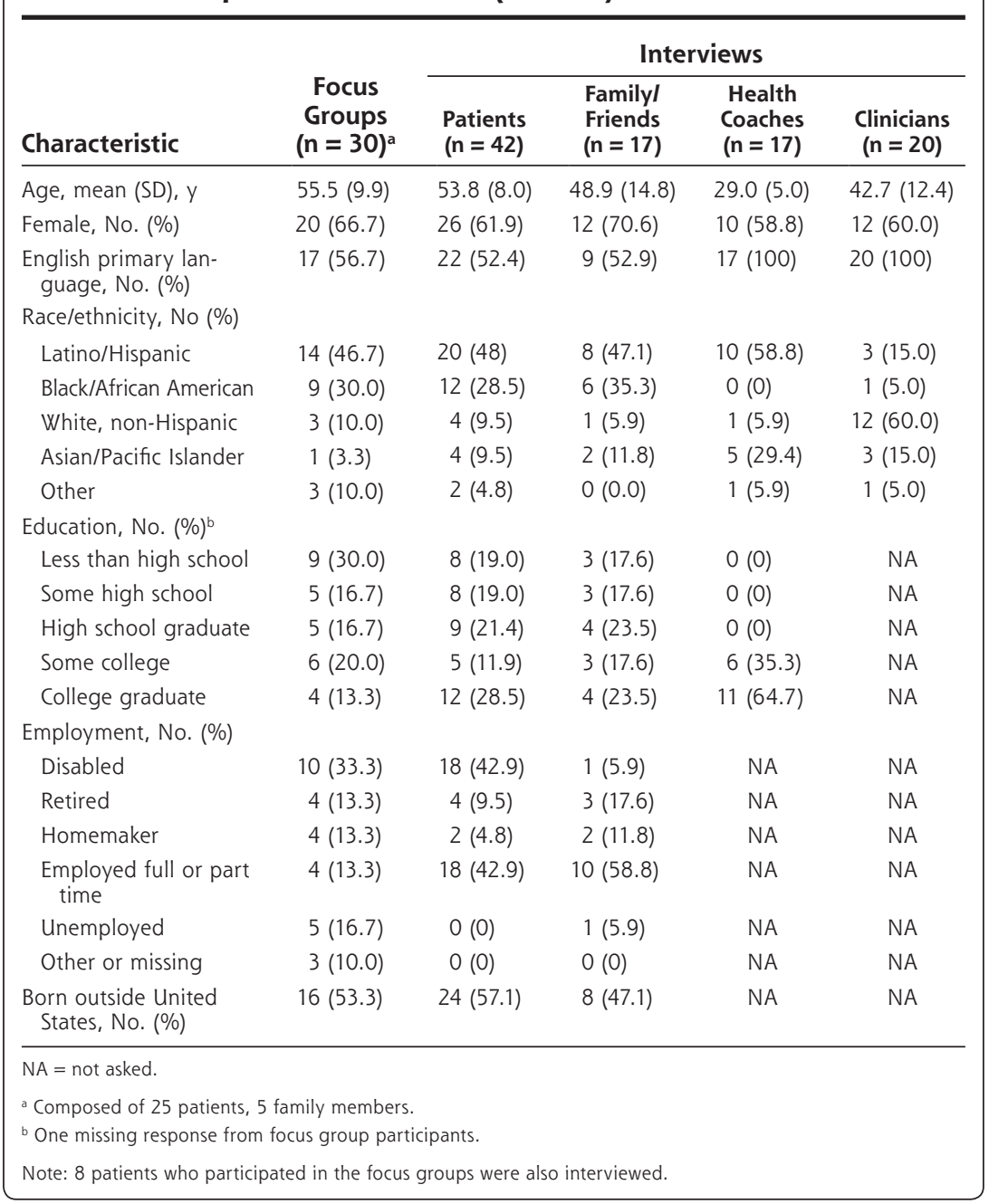




\section{Themes Identified}

From our analysis, we identified 7 themes, discussed below. Each of the 4 groups interviewed (patients, family and friends, health coaches, and clinicians) contributed to all themes, although not necessarily to the same degree. Table 2 describes each theme in more detail and provides a count for the number of times individual members of each group contributed comments for the theme.

\section{Shared Characteristics Between Health Coaches and Patients}

Congruence between the patient and health coach in language, culture, and life experience was seen as important to helping the patient feel comfortable with and understood by, and therefore more likely to work with the coach to make health decisions. As one coach said, "They saw me more as a peer... I think it was an advantage because I could understand them or relate to them better and they saw that. It was comforting for them. They trusted me more." A patient stated, "[I was] extraordinarily lucky to get the health coach there who is Hispanic and black like me... And she understands my culture. We don't need to find out, 'Oh, what do you eat?' She knows already."

\section{Availability of Health Coaches to Patients}

Availability, including frequency of contacts, the duration of the relationship, and accessibility of the health coach, was seen as important in establishing a positive relationship needed for effective support. As one patient stated, "I felt very comfortable and excited working with [health coach], and there was also the time factor because we used to meet every 2 weeks." This was echoed by family members and friends, one of whom said, "I heard that... she [patient] would call her [name of coach] up or she would ... always come with her whenever she needed her." Coaches also mentioned the importance of spending time with the patient: "We have the luxury of having an hour visit. So, during that hour, we talk and talk. You ask and ask and ask. And then, so, you get to know. And you see the body language. And then little by little, the patients feel comfortable."

\section{Establishing a Trusting Relationship}

A positive relationship based on trust was seen as central to the coach's ability to support the patient. A trusting relationship enabled patients to be honest, ask questions, and express doubts or disagreements, which allowed the health coach to be more effective. As a coach put it,

If I have a patient that doesn't confide in me or that doesn't trust me, I'm never going to get anything out of them. A patient would probably tell me the things I want to hear and not the things that are really happening, and then I wouldn't be able to help the patient that well.

Related to trust was the issue of confidentiality of the information the patient shared with the health coach, usually around medications. Health coaches were uncomfortable with these situations and reported trying to convince the patient to share the information with the clinician. If the patient did not agree to reveal the information, some coaches respected that in order to preserve the relationship: "So, she told me not to tell her provider. She said, 'I'm taking this medication [vitamins]. Don't tell my provider ... It's my secret medicine.' So, I never told the provider. I kept my word." In contrast another coach felt compelled to tell the clinician, saying, "They would tell me something, they'd be like, 'Oh, don't tell my doctor I didn't take the medications.' But I was like, 'I have to. This is... You know... we're a team."'

The relationship between trust and coaching activities (described below) was seen as iterative. Although trust made coaching possible, coaching also built trust. As one coach put it, "He [the patient] told me, 'If you do that [call to remind him of appointments], I'll do my part.' It was kind of like, teamwork the whole time. ... I felt like he was telling me, you keep your word, and I'll keep mine."

\section{Educational Role of the Health Coach}

To make informed decisions, patients need to have a basic understanding of their condition, their options, and the consequences of each option. Health coaches provided education using patient-centered techniques that included determining patients' goals and readiness for change and checking for patients' understanding. Education was seen as playing a critical role in coaching support. In the words of one patient, "She made it where I understood it, you know... She just sat down and explained to me what the consequences werewhat it could be whether I did it or not." Clinicians also appreciated the patient education health coaches provided: "He had been educated really well by the health coach and she helped him with so many things. She had helped him with diet, exercise, with methods to improve his insulin adherence." Health coaches noted that patient education was often key to helping patients: "The more information you gave him, the more that he understood and the more it made sense to him, and then he's kind of like, 'Okay, it makes sense' and then he would make better decisions."

\section{Providing Personal Support for the Patient}

Both patients and coaches frequently noted the importance of the personal support provided by the coaches. Personal support includes valuing the patient, which 
Table 2. Description of Themes for Patient Decision Making With Health Coaches

\begin{tabular}{|c|c|c|c|c|}
\hline Theme & Description & Components & $\begin{array}{l}\text { Relationship to Patient's } \\
\text { Decision Making }\end{array}$ & $\begin{array}{l}\text { Participants (No.) } \\
\text { Sharing Experiences } \\
\text { Identified for Theme }\end{array}$ \\
\hline $\begin{array}{l}\text { Shared char- } \\
\text { acteristics }\end{array}$ & $\begin{array}{l}\text { Demographic } \\
\text { characteristics } \\
\text { and life experi- } \\
\text { ences shared } \\
\text { by patient and } \\
\text { health coach }\end{array}$ & $\begin{array}{l}\text { Shared language, culture, and sex } \\
\text { Similar social status, experiences, and } \\
\text { values }\end{array}$ & $\begin{array}{l}\text { Shared characteristics may help } \\
\text { the patient feel more comfort- } \\
\text { able with and understood by } \\
\text { health coach and therefore } \\
\text { more likely to work with coach } \\
\text { to make health decisions }\end{array}$ & $\begin{array}{l}\text { Patients (6) } \\
\text { Family/friends (1) } \\
\text { Health coaches (13) } \\
\text { Clinicians (11) }\end{array}$ \\
\hline Availability & $\begin{array}{l}\text { Health coach } \\
\text { being available } \\
\text { to the patient }\end{array}$ & $\begin{array}{l}\text { Frequency of contacts } \\
\text { Duration of contacts } \\
\text { Continuity over time } \\
\text { Being accessible to patient } \\
\text { Proactively contacting patient }\end{array}$ & $\begin{array}{l}\text { Health coach's ongoing contact } \\
\text { with patient helps build the } \\
\text { relationship and allows for } \\
\text { reinforcement and support of } \\
\text { patient's decisions }\end{array}$ & $\begin{array}{l}\text { Patients (32) } \\
\text { Family/friends (5) } \\
\text { Health coaches (16) } \\
\text { Clinicians (14) }\end{array}$ \\
\hline $\begin{array}{l}\text { Trusting } \\
\text { relation- } \\
\text { ship }\end{array}$ & $\begin{array}{l}\text { Positive, trust- } \\
\text { ing relation- } \\
\text { ship between } \\
\text { health coach } \\
\text { and patient }\end{array}$ & $\begin{array}{l}\text { Patient trust in health coach } \\
\text { Health coach trust in patient } \\
\text { Factors that create or reinforce trust } \\
\text { Consequences of trust }\end{array}$ & $\begin{array}{l}\text { Trust makes patient more will- } \\
\text { ing to confide in and accept } \\
\text { support from health coach } \\
\text { around health decisions }\end{array}$ & $\begin{array}{l}\text { Patients (29) } \\
\text { Family/friends (5) } \\
\text { Health coaches (17) } \\
\text { Clinicians (9) }\end{array}$ \\
\hline Education & $\begin{array}{l}\text { Health coach } \\
\text { educates } \\
\text { patient in } \\
\text { person and } \\
\text { through writ- } \\
\text { ten materials }\end{array}$ & $\begin{array}{l}\text { Providing patients with basic information } \\
\text { about his/her condition and explaining } \\
\text { how his/her behaviors affect it } \\
\text { Describing options and possible } \\
\text { consequences } \\
\text { Explaining purpose of medication }\end{array}$ & $\begin{array}{l}\text { Education provides a foundation } \\
\text { to effective decision making; } \\
\text { patients need to understand } \\
\text { their options and how their } \\
\text { choices affect their health }\end{array}$ & $\begin{array}{l}\text { Patients (28) } \\
\text { Family/friends (4) } \\
\text { Health coaches (14) } \\
\text { Clinicians (6) }\end{array}$ \\
\hline $\begin{array}{l}\text { Personal } \\
\text { support }\end{array}$ & $\begin{array}{l}\text { Health coach } \\
\text { provides emo- } \\
\text { tional support, } \\
\text { engages with } \\
\text { patient, makes } \\
\text { personal com- } \\
\text { mitment to } \\
\text { help patient }\end{array}$ & $\begin{array}{l}\text { Caring about and valuing patient } \\
\text { Listening to and understanding patient } \\
\text { Allaying patients' fears } \\
\text { Providing hope and confidence } \\
\text { Encouraging and empowering patient } \\
\text { Motivating patient using encourage- } \\
\text { ment, reminders, connecting actions } \\
\text { to outcomes }\end{array}$ & $\begin{array}{l}\text { Providing a supportive relation- } \\
\text { ship allows patient to disclose } \\
\text { more, be more honest about } \\
\text { goals, barriers, and decisions; } \\
\text { active listening helps the } \\
\text { patient process information, } \\
\text { express needs and emotions; } \\
\text { patient may be more likely to } \\
\text { care for self when feels cared } \\
\text { for by health coach; motivated } \\
\text { patients more likely to make } \\
\text { and carry out decisions }\end{array}$ & $\begin{array}{l}\text { Patients (33) } \\
\text { Family/friends (6) } \\
\text { Health coaches (17) } \\
\text { Clinicians (8) }\end{array}$ \\
\hline $\begin{array}{l}\text { Decision } \\
\text { support }\end{array}$ & $\begin{array}{l}\text { Pragmatic } \\
\text { support for } \\
\text { patient to } \\
\text { make and } \\
\text { carry out } \\
\text { health decision }\end{array}$ & $\begin{array}{l}\text { Helping patient identify goals } \\
\text { Helping create action plans } \\
\text { Checking back with patient } \\
\text { Identifying barriers and problem solving } \\
\text { Encouraging small steps } \\
\text { Helping patient get prescription filled } \\
\text { Helping patient make and keep } \\
\text { appointments }\end{array}$ & $\begin{array}{l}\text { Using specific methods and } \\
\text { techniques from coach train- } \\
\text { ing to help patient identify } \\
\text { their goals and choose an } \\
\text { action plan to move toward } \\
\text { those goals; makes it easier } \\
\text { for patients to get what they } \\
\text { need to carry out their deci- } \\
\text { sion, thereby increasing range } \\
\text { of options }\end{array}$ & $\begin{array}{l}\text { Patients (28) } \\
\text { Family/friends (5) } \\
\text { Health coaches (16) } \\
\text { Clinicians (10) }\end{array}$ \\
\hline $\begin{array}{l}\text { Bridging as } \\
\text { part of the } \\
\text { theme }\end{array}$ & $\begin{array}{l}\text { Health coach } \\
\text { acts as a liai- } \\
\text { son or bridge } \\
\text { between } \\
\text { patient and } \\
\text { primary care } \\
\text { clinician }\end{array}$ & $\begin{array}{l}\text { Helping patient communicate with } \\
\text { clinician } \\
\text { Providing clinician with information } \\
\text { about patient } \\
\text { Clarifying clinician's communication to } \\
\text { patient } \\
\text { Checking with patient between visits } \\
\text { about treatment plan } \\
\text { Helping patient to disclose to clinician } \\
\text { Reducing patient's fear of physician }\end{array}$ & $\begin{array}{l}\text { Health coach can help } \\
\text { strengthen the patient-clini- } \\
\text { cian relationship and improve } \\
\text { patient-clinician communica- } \\
\text { tion leading to more informed } \\
\text { and shared decision making } \\
\text { between patient and clinician }\end{array}$ & $\begin{array}{l}\text { Patients (18) } \\
\text { Family/friends (4) } \\
\text { Health coaches (15) } \\
\text { Clinicians (16) }\end{array}$ \\
\hline
\end{tabular}

helps the patient value himself or herself enough to make decisions and take actions to improve their health. Personal support was also essential to providing a patient with the confidence to make changes and overcome emotional barriers to change. As one patient put it, "I thought, 'Wow, this person's thinking about me.' So, I'm thinking if other people are thinking about me, then I really need to think about myself. You feel better about the disease, and about the situation you're in." Another patient stated with regard to her diabetes, "It's more manageable. It's not like a death sentence... It makes you feel like you can... handle it. You can 
deal with it." Health coaches also saw personal support as instrumental to helping patients set goals and make changes; as one stated, "If we focused on the diabetes and completely ignored her emotional issues, we wouldn't get anywhere."

\section{Providing Support for Decision Making}

The theme of decision support included working with patients to identify options, create action plans, identify and overcome barriers, locate resources, and provide reminders. By providing this support, coaches enabled patients a wider range of choices. Although coaches identified options and made suggestions, it was essential that the choice was the patient's own. In the words of one coach,

I always say, "I'm not here to tell you what to do. I'm here to offer you options.... What could you do to help you get better or to achieve the goals you want? You are more than free to say, "I want to do this. I don't want to do this; I want to try this instead."

Patients recognized this principle as well; as one said, "We negotiate. But ultimately her [the coach's] philosophy is that the patient has the life choices."

\section{Bridging Between the Patient and Clinician}

The last theme refers to coaches working in conjunction with the clinicians to support patient decisions. It included improving patient understanding and communication with the clinician, helping the patient identify and ask questions of the clinician, supporting the patient between visits, and reducing the patient's fear and anxiety around office visits. Two comments from patients illustrate the importance of this function: "She bridges the gap during the time ... the health coach is the bridge for that time between appointments" and "I felt supported because there was a relationship, something that helped me stay connected with the doctor because of her, she was the bridge, I felt supported, and I liked it." Family members shared this perception. "I know she [the patient] would always tell me that .... If the doctor didn't understand what she needed [the health coach] would be there as support for her if she wanted to say something to the doctor." Health coaches believed their bridging role helped patients feel like more of an active partner in their care. "I think patients come in thinking they're not part of the team. They're just being told what to do.
It's a paradigm shift altogether. 'Okay, I'm supposed to be part of this decision making."' Clinicians also recognized the role of the health coach in supporting their relationship with the patient. "I think of the health coaches as being almost like a liaison between me and the patients. If I haven't explained something well or can't do follow-up or can't reinforce a message, I'm hoping the health coach can do that."

\section{Conceptual Model}

Figure 1 shows the relationship between the 7 themes identified as a conceptual model of how health coaches work with patients to support health decisions and actions. The relationship between the patient and health coach, particularly the degree of trust, is central to effective coaching. Shared characteristics and the frequency, duration, and nature of contacts were important for initiating a trusting relationship, which provided the basis for effective health coaching. Health coaching activities that supported patient decision making are grouped into 4 broad themes of education, personal support, direct decision support, and acting as a bridge between patients and their clinician. These activities in turn strengthen the relationship between the coach and the patient.

\section{DISCUSSION}

In this study, we sought to understand the process of health coaching by examining the experiences and beliefs of patients, family members, health coaches, and clinicians. Our analysis yielded a conceptual model that characterizes how health coaches and patients work together. There are multiple theories of health promotion and behavioral change, many of which

\section{Figure 1. Conceptual model of the process of health coaching to support patients' health-related decisions and behavioral change.}

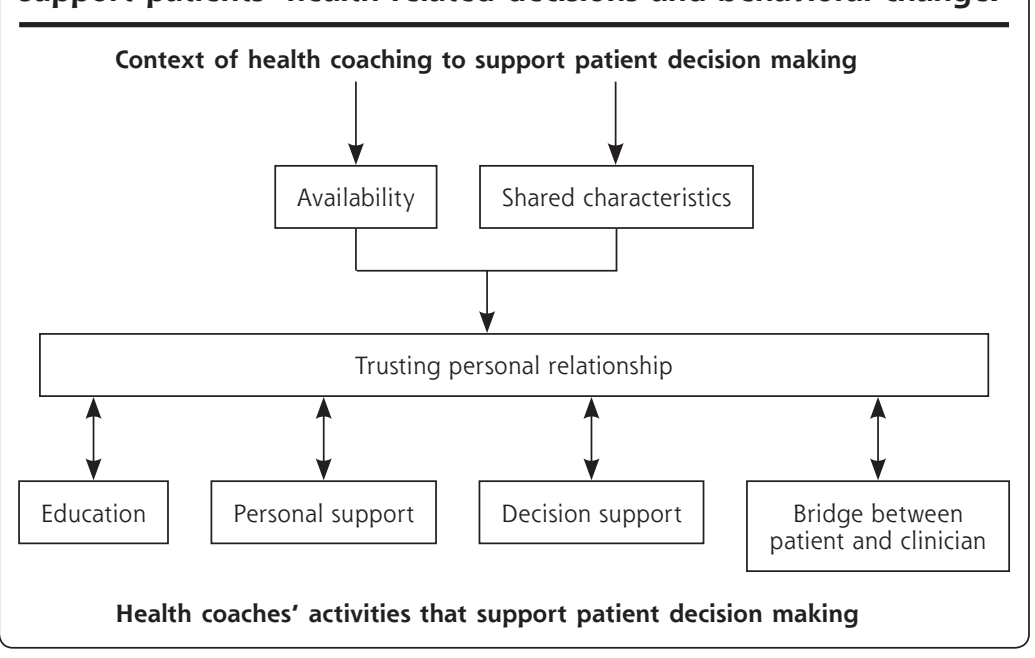


model internal processes of decision making (eg, the health belief mode ${ }^{29}$ and theory of reasoned action ${ }^{30}$ ), whereas others emphasize the role of external factors (eg, the Tannahill model ${ }^{31}$ ). Perhaps the most relevant comparison for our study is the integrated theory of health behavior change (ITHBC) developed from a synthesis of the literature for support of behavioral change, including existing models and empirical evidence. ${ }^{32}$ In the ITHBC model, knowledge, beliefs, and social facilitation contribute to the ability of patient to engage in goal setting, decision making, planning, and self-monitoring leading to sustained behavioral changes. A primary difference between this model and ours is the centrality of the patient-coach relationship in our model, whereas social support from existing relationships features prominently in the ITHBC model.

This central role of the coach-patient relationship in our model is consistent with that noted in previous studies of nursing support. Howard and Hagen, ${ }^{33}$ exploring the experiences of 3 people with type 2 diabetes, found that caring and supportive relationships with the nurse coach increased their self-management. Parry and colleagues $^{34}$ found that caring relationships between patients and their nurse health coaches helped them feel more invested in their care transitions. A recent qualitative study of the roles of community health workers (CHWs) in facilitating behavioral change among Filipino patients found similar themes: the importance of congruence in culture, language, and life experiences in establishing trust and rapport; a combination of social support and help with adopting healthy behaviors; and the central role of the partnership between the CHWs and patients. ${ }^{35}$ Because these $\mathrm{CHWs}$ were community based, they did not perform the bridging functions that we noted. Our study takes a further step toward understanding the development of a strong, trusting relationship with a health coach and how a strong relationship provides the basis for effective coaching.

We also found that the peer-like relationship between patients and health coaches was important for establishing a closer, trusting relationship where patients felt able to be more open and engaged, in contrast to the inequality in social power between patients and clinicians. Health coaches often supported patients by acting as a bridge between them and their clinician, thereby reducing the power differential. These observations fit well with a recent review that found power inequality between patients and clinicians to be a major barrier to patient participation in shared decision making. ${ }^{36}$

The issue of confidentiality between patients and health coaches is worth noting, as it apparently has not been previously reported. Without specific guidance from their training, the health coaches in the current study took different approaches to this issue, with one health coach believing she needed to report anything the patient told her relevant to the patient's health to the physician, while another chose to honor confidentiality with the patient. The issue of confidentiality is an example of the larger issue of the definition of the health coach's role. Although it was not a focus of the current study, we have previously noted the challenges health coaches face when embracing a new and often unfamiliar role. ${ }^{37}$ One them is being an advocate for the patient while also maintaining a good working relationship with the patient's clinician. In our clinic networks, coaches commonly work with patients on goals consistent with the care plan made with the clinician, a role clinicians seem to value. ${ }^{38}$ Coaches provide education, emotional, and practical support, but not medical advice. Adherence to this role is evaluated in testing and direct observation, and is reinforced by coaching supervisors.

Our study was purposefully limited to patient decision making around goal setting, behaviors, and action plans, rather than larger medical decisions for which the benefits of coaching are more clear. ${ }^{39,40}$ In addition, the study was conducted with public health safety-net clinics, and coaches were trained using a well-developed curriculum, the generalizability of our findings to other populations and to health coaches with different training is not known.

In summary, we identified a set of themes or core features of successful coaching: peer relationship, availability and continuity, a strong relationship based on mutual trust, providing personal as well as practical support, and bridging between patients and their clinician. It is encouraging that all groups cited these aspects of health coaching. These themes and the conceptual model can be used in training and supporting health coaches. The issue of patient confidentiality should be dealt with proactively in health coach training as part of the larger issue of defining the role of the health coach as both a patient advocate and a member of the care team.

To read or post commentaries in response to this article, see it online at http://www.annfammed.org/content/14/6/509.

Key words: health coaching; allied health personnel; patient decision making; self-management support; patient-centered care; qualitative research; primary care; practice-based research

Submitted January 16, 2016; submitted, revised, April 30, 2016; accepted May 24, 2016.

Funding support: This study was supported by an award from the Patient Centered Outcomes Research Institute.

Acknowledgments: The authors wish to acknowledge support of the UCSF Center for Excellence in Primary Care, especially Dr Kevin Grumbach and Dr Thomas Bodenheimer.

Supplementary materials: Available at http://www.AnnFamMed. org/content/14/6/509/suppl/DC1/. 


\section{References}

1. Bodenheimer T, Willard-Grace R, Ghorob A. Expanding the roles of medical assistants: who does what in primary care? JAMA Intern Med. 2014;174(7):1025-1026.

2. Ghorob A. Health coaching: teaching patients how to fish. Fam Pract Manag. 2013;20(3):40-42.

3. Brodin N, Eurenius E, Jensen I, Nisell R, Opava $\mathrm{CH}_{\text {; PARA Study }}$ Group. Coaching patients with early rheumatoid arthritis to healthy physical activity: a multicenter, randomized, controlled study. Arthritis Rheum. 2008;59(3):325-331.

4. Benzo R, Vickers K, Novotny PJ, et al. Health coaching and chronic obstructive pulmonary disease re-hospitalization. A randomized study. Am J Respir Crit Care Med. 2016;194(6):672-680.

5. Thom DH, Ghorob A, Hessler D, De Vore D, Chen E, Bodenheimer TA. Impact of peer health coaching on glycemic control in lowincome patients with diabetes: a randomized controlled trial. Ann Fam Med. 2013;11(2):137-144

6. Turner BJ, Hollenbeak CS, Liang Y, Pandit K, Joseph S, Weiner MG. A randomized trial of peer coach and office staff support to reduce coronary heart disease risk in African-Americans with uncontrolled hypertension. J Gen Intern Med. 2012;27(10):1258-1264.

7. Daaleman TP, Fisher EB. Enriching patient-centered medical homes through peer support. Ann Fam Med. 2015;13(Suppl 1):S73-S78.

8. Fisher EB, Ballesteros J, Bhushan N, et al. Key features of peer support in chronic disease prevention and management. Health Aff (Millwood). 2015;34(9):1523-1530.

9. Ruggiero L, Moadsiri A, Butler P, et al. Supporting diabetes selfcare in underserved populations: a randomized pilot study using medical assistant coaches. Diabetes Educ. 2010;36(1):127-131.

10. Willard-Grace R, Chen EH, Hessler D, et al. Health coaching by medical assistants to improve control of diabetes, hypertension, and hyperlipidemia for low-income patients: a randomized controlled trial. Ann Fam Med. 2015;13(2):130-138.

11. Fisher EB, Strunk RC, Highstein GR, et al. A randomized controlled evaluation of the effect of community health workers on hospitalization for asthma. Arch Pediatr Adoles Med. 2009;163(3):225-232.

12. Balaban RB, Galbraith AA, Burns ME, Vialle-Valentin CE, Larochelle MR, Ross-Degnan D. A patient navigator intervention to reduce hospital readmissions among high-risk safety-net patients: a randomized controlled trial. J Gen Intern Med. 2015;30(7):907-915.

13. Babamoto KS, Sey KA, Camilleri AJ, Karlan VJ, Catalasan J, Morisky DE. Improving diabetes care and health measures among Hispanics using community health workers: results from a randomized controlled trial. Health Educ Behav. 2009;36(1):113-126.

14. Palmas W, March D, Darakjy S, et al. Community health worker interventions to improve glycemic control in people with diabetes: a systematic review and meta-analysis. J Gen Intern Med. 2015;30(7): 1004-1012.

15. Philis-Tsimikas A, Fortmann A, Lleva-Ocana L, Walker C, Gallo LC. Peer-led diabetes education programs in high-risk Mexican Americans improve glycemic control compared with standard approaches: a Project Dulce promotora randomized trial. Diabetes Care. 2011; 34(9):1926-1931.

16. Spencer MS, Rosland AM, Kieffer EC, et al. Effectiveness of a community health worker intervention among African American and Latino adults with type 2 diabetes: a randomized controlled trial. Am J Public Health. 2011;101(12):2253-2260.

17. Ivey SL, Tseng W, Kurtovich $E$, et al. Evaluating a culturally competent health coach intervention for Chinese-American patients with diabetes. Diabetes Spectr. 2012;25(2):93-102.

18. Margolius D, Bodenheimer $\mathrm{T}$, Bennett $\mathrm{H}$, et al. Health coaching to improve hypertension treatment in a low-income, minority population. Ann Fam Med. 2012;10(3):199-205.

19. Kivelä K, Elo S, Kyngäs H, Kääriäinen M. The effects of health coaching on adult patients with chronic diseases: a systematic review. Patient Educ Couns. 2014;97(2):147-157.
20. Thackeray R, Merrill RM, Neiger BL. Disparities in diabetes management practice between racial and ethnic groups in the United States. Diabetes Educ. 2004;30(4):665-675.

21. Chapman S, Marks A, Chan M. Research Brief: The Increasing Role of Medical Assistants in Small Primary Care Physician Practice: Key Issues and Policy Implications. San Francisco, CA: Center for the Health Professions, University of California San Francisco; 2010.

22. Bennett HD, Coleman EA, Parry C, Bodenheimer T, Chen EH. Health coaching for patients with chronic illness. Fam Pract Manag. 2010;17(5):24-29.

23. UCSF Center for Excellence in Primary Care. Health coaching. http:// cepc.ucsf.edu/health-coaching. Accessed Oct 15, 2016.

24. Wagner EH, Austin BT, Von Korff M. Organizing care for patients with chronic illness. Milbank Q. 1996;74(4):511-544.

25. Prochaska JO, Velicer WF. The transtheoretical model of health behavior change. Am J Health Promot. 1997;12(1):38-48.

26. Linden A, Butterworth SW, Prochaska JO. Motivational interviewing-based health coaching as a chronic care intervention. J Eval Clin Pract. 2010;16(1):166-174.

27. Strauss A, Corbin J. Basics of Qualitative Research: Grounded Theory: Procedures and Techniques. Newbury Park, CA: Sage Publications; 1990.

28. Patton MQ. Enhancing the quality and credibility of qualitative analysis. Health Serv Res. 1999;34(5 Pt 2):1189-1208.

29. Janz NK, Becker MH. The health belief model: a decade later. Health Educ Q. 1984;11(1):1-47.

30. Ajzen I, Albarracin D, Hornick R, eds. Prediction and Change of Health Behavior: Applying the Reasoned Action Approach. Mahwah, NJ: Lawrence Erlbaum Associates; 2007.

31. Tannahill A. Health promotion: the Tannahill model revisited. Public Health. 2009;123(5):396-399.

32. Ryan P. Integrated theory of health behavior change: background and intervention development. Clin Nurse Spec. 2009;23(3):161-170, quiz 171-172.

33. Howard LM, Hagen BF. Experiences of persons with type II diabetes receiving health coaching: an exploratory qualitative study. Educ Health (Abingdon). 2012;25(1):66-69.

34. Parry C, Kramer HM, Coleman EA. A qualitative exploration of a patient-centered coaching intervention to improve care transitions in chronically ill older adults. Home Health Care Serv Q. 2006;25(3-4): 39-53.

35. Katigbak C, Van Devanter N, Islam N, Trinh-Shevrin C. Partners in health: a conceptual framework for the role of community health workers in facilitating patients' adoption of healthy behaviors. Am J Public Health. 2015;105(5):872-880.

36. Joseph-Williams N, Elwyn G, Edwards A. Knowledge is not power for patients: a systematic review and thematic synthesis of patientreported barriers and facilitators to shared decision making. Patient Educ Couns. 2014;94(3):291-309.

37. Willard-Grace R, Najmabadi A, Araujo C, et al. "I Don't See Myself as a Medical Assistant Anymore": Learning to Become a Health Coach, in our Own Voices. i.e.: inquiry in education. Digital Commons at NLU. 2013;4(2). http://digitalcommons.nl.edu/ie/vol4/iss2/2. Published Nov 11, 2013. Accessed Oct 15, 2016.

38. Dubé K, Willard-Grace R, O'Connell B, et al. Clinician perspectives on working with health coaches: a mixed methods approach. Fam Syst Health. 2015;33(3):213-221.

39. Stacey D, Kryworuchko J, Bennett C, Murray MA, Mullan S, Légaré F. Decision coaching to prepare patients for making health decisions: a systematic review of decision coaching in trials of patient decision AIDS. Med Decis Making. 2012;32(3):E22-E33.

40. Elwyn G, Frosch D, Volandes AE, Edwards A, Montori VM. Investing in deliberation: a definition and classification of decision support interventions for people facing difficult health decisions. Med Decis Making. 2010;30(6):701-711. 